\title{
Intraseasonal SST-precipitation relationship in a coupled reanalysis experiment using the MRI coupled atmosphere-ocean data assimilation system
}

\author{
Chiaki Kobayashi $^{1}$ (D) Y Yosuke Fujii ${ }^{1}$ (D) $\cdot$ Ichiro Ishikawa $^{1}$ D
}

Received: 27 May 2020 / Accepted: 15 December 2020 / Published online: 8 January 2021

(c) The Author(s) 2021

\begin{abstract}
To evaluate the atmosphere-ocean coupled data assimilation system developed at the Meteorological Research Institute, the lead-lag relation between the intraseasonal variations (with a time scale of 20-100 days) in precipitation and sea surface temperature (SST) is examined in the tropics. It is shown that the relationship over the tropical western Pacific in the coupled reanalysis experiment (CDA) follows the observed relationship more closely than that in the uncoupled reanalysis experiment (UCPL). However, the lead-lag correlations with the observed SST are almost identical between precipitations in CDA and UCPL, indicating that the atmospheric component is strongly constrained by atmospheric observations and hardly affected by the SSTs as boundary conditions. Better representation of the SST-precipitation relationship in CDA is, thus, mostly due to the SST variation modified by the model physics. Comparison with additional reanalysis experiments using coupled and uncoupled systems that assimilate only in-situ observations without satellite observations suggests that the coupled model's physics complements the relatively weak observation constraints and reduces the degradation of the SST-precipitation relationship. Additional analysis for CDA suggests that the warming-to-cooling (cooling-to-warming) transition of the surface net flux, which is in phase with precipitation, is delayed from the positive (negative) peak of SST due to downward heat propagation in the ocean. Comparison of the oceanic near-surface temperature field with observation data indicates that the downward propagation of heat signals is too fast in CDA, resulting in smaller lags of transitions of the net heat flux and precipitation behind SST peaks.
\end{abstract}

Keywords Atmosphere-ocean interaction · Intraseasonal variation $\cdot$ SST-precipitation relationship · Coupled data assimilation $\cdot$ Coupled climate model

\section{Introduction}

The initial fields of a global coupled atmosphere-ocean model are often obtained by combining the atmospheric and oceanic parts, which are analyzed separately (e.g. Balmaseda and Anderson 2009; MacLachlan et al. 2015; Hudson et al.

Supplementary Information The online version contains supplementary material available at https://doi.org/10.1007/s0038 2-020-05592-w.

\section{Chiaki Kobayashi}

ckobayas@mri-jma.go.jp

Yosuke Fujii

yfujii@mri-jma.go.jp

Ichiro Ishikawa

iishikaw@mri-jma.go.jp

1 Meteorological Research Institute, 1-1 Nagamine, Tsukuba, Ibaraki 305-0052, Japan
2017; Takaya et al. 2018; Johnson et al. 2019). Therefore, when making predictions using such a model, it is inferred that these combined initial fields have inconsistencies near the interface between the atmosphere and the ocean, which would cause drifts in the sea surface temperature (SST) and biases in the precipitation at the beginning of the prediction (Balmaseda and Anderson 2009). A phenomenon in which these biases grow rapidly is called "coupling shock" or "initial shock". In order to reduce this "initial shock", it is necessary to create initial fields in which the atmosphere and the ocean are in appropriate balance and a coupled 
atmosphere-ocean assimilation system is considered promising for producing such balanced initial fields (Mulholland et al. 2015).

Although precipitation in reanalysis products is not a direct assimilation result, but an output from the initial part of the model forecast in the data assimilation cycle, it is a variable that represents the comprehensive performance of the assimilation system. As an indicator of the accuracy of the atmospheric reanalysis system, the relationship between SST and precipitation ("SST-P relationship", hereafter), which is the result of atmosphere-ocean interaction, has been investigated. For example, Arakawa and Kitoh (2004) showed that local precipitation fluctuation lags two pentads behind SST over large areas of the tropical oceans in their observation. However, the National Centers for Atmospheric Prediction (NCEP) and the National Center for Atmospheric Research (NCAR) reanalysis dataset ("NCEP1"; Kalnay et al. 1996) could not capture the observed SST-P relationship. Arakawa and Kitoh (2004) speculate that the relationship is caused by the specification of the observed SST as the lower boundary condition in the numerical model of the data assimilation system, and insufficiency of observation data assimilated in the system, that is, atmospheric reanalysis prescribed by the observed SST does not simulate actual precipitation behavior due to various problems in the model and data assimilation system. Fujii et al. (2009) reported that the observed SST-P relationship is represented in the semi-coupled assimilation system, which assimilates only ocean observation data to the coupled atmosphere-ocean model, although the atmospheric model simulation forced with observed SST (so-called AMIP run) could not reproduce the observed relationship.

In addition, Saha et al. (2010) compared the relationship between simulated SST and precipitation in the equatorial western Pacific among reanalysis datasets and indicated that the Climate Forecast System Reanalysis (CFSR) represents the observed SST-P relationship better than either the NCEP1 or the NCEP2 (NCEP Department of Energy (DOE) AMIP-II Reanalysis, Kanamitsu et al. 2002). Saha et al. (2010) argued that this result was obtained because the CFSR is generated by a coupled atmosphere-ocean data assimilation system. However, a later study by Kumar et al. (2013) showed that the ERA-Interim (Dee et al. 2011) and MERRA (Rienecker et al. 2011), which are generated by uncoupled atmospheric data assimilation systems, well represent the observed SST-P relationship. Kumar et al. (2013) also pointed out that the improvement in SST-P relationship in CFSR shown in Saha et al. (2010) cannot be confirmed when a single SST dataset is used in computation of the relationship instead of SST used in each reanalysis.

Feng et al. (2018) evaluated the coupling effect in representation of SST-P intraseasonal relationships through comparison between the European Centre for Medium-Range
Weather Forecasts (ECMWF) coupled climate reanalysis (CERA-20C) and the ECMWF atmosphere-only climate reanalysis (ERA-20C). In these reanalyses, only surface meteorological observations are assimilated in the atmospheric component. Feng et al. (2018) showed a better representation of the SST-P relationship in CERA-20C than in ERA-20C, and argued that the improvement is not due to coupling and instead is due to CERA-20C including short timescale SST variability not present in ERA-20C which uses a monthly product.

In this study, we evaluate a short-term reanalysis experiment produced by the coupled atmosphere-ocean data assimilation system (Fujii et al. 2019, 2021), developed by the Meteorological Research Institute (MRI). This system is based on Japan Meteorological Agency (JMA)'s operational atmospheric data assimilation system and JMA's operational global ocean data assimilation system. We focus on the SST-P relationship of intraseasonal variation through comparison with the Japanese 55-year Reanalysis (JRA-55; Kobayashi et al. 2015) and non-coupled data assimilation experiment. The atmospheric component uses all available observations for assimilation, including upper-air observations and satellite observations, which are the same observation sets as JRA-55. The uncoupled data assimilation experiment is carefully designed for comparison with the coupled experiment, so that the two experiments differ only in the lower boundary of the atmosphere. The lower boundary of the atmosphere is either the active ocean component, or the prescribed SST analysis, which is the same as the one assimilated into the ocean component in the coupled experiment. We also evaluate the difference between coupled and non-coupled data assimilation experiments without satellite observations in order to examine the sensitivity to the strength of the atmospheric constraint by data assimilation. Then, the process determining the SST's intraseasonal variation in the coupled experiment is examined through the analysis of the sea surface heat flux.

\section{Data and methods}

We performed a 2-year reanalysis experiment using the coupled atmosphere-ocean data assimilation system version 1 (MRI-CDA1, Fujii et al. 2019, 2021). In this coupled data assimilation system, the assimilation procedure (see Fig. 1) consists of two phases. The first phase is named "the onlyatmosphere assimilation coupled ocean-atmosphere general circulation model (CGCM) run" (indicated by a green arrow in Fig. 1). The second phase is "the atmosphere-ocean assimilation CGCM run" (indicated by the red arrow in Fig. 1). In the first phase, while the coupled model is integrated for 5 days from 'day 0', the state of the atmospheric component is replaced by the atmospheric four-dimensional 


\section{Procedure of the MRI-CDA1 assimilation}

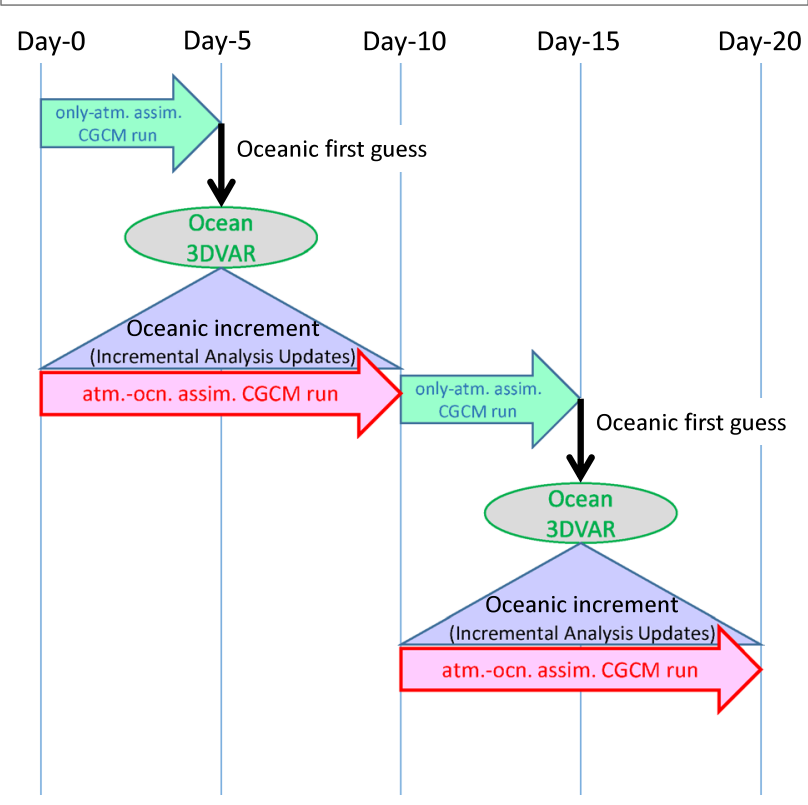

Fig. 1 Schematic diagram illustrating the assimilation procedure in the MRI-CDA1

variational (4DVAR) data assimilation result every $6 \mathrm{~h}$, and the oceanic component freely evolves without assimilation. The final state of the ocean is used as the first guess of the oceanic three-dimensional variational (3DVAR) analysis, in which observation data between 'day 0 ' and 'day 10' are utilized. In the second phase, the coupled model is again integrated for 10 days from the same 'day 0' in the same manner as the first phase (i.e., with six-hourly atmospheric data assimilation), except the increments generated by the oceanic 3DVAR analysis are added to the ocean component through incremental analysis updates (IAU; Bloom et al. 1996). The oceanic and atmospheric outputs of the second phase are the final products of the data assimilation system. Note that the assimilation intervals of the atmospheric and oceanic components are different ( $6 \mathrm{~h}$ and 10 days, respectively). Following the definition described in Penny et al. (2017), this system is classified as an atmosphere-ocean "quasi-strongly" coupled data assimilation system, since atmosphere and ocean analyses covering the same valid time influence each other, although they are conducted separately with uncoupled analysis procedures.

This MRI-CDA1 system consists of three major components. The atmosphere analysis system is a global atmospheric four-dimensional data assimilation system used in the JMA's operational numerical weather prediction (JMA 2013), and forms the first component. Its inner model based on Global Spectral Model applies TL159 horizontal resolution (approximately $110 \mathrm{~km}$ ) with 100 vertical levels (model top is $0.01 \mathrm{hPa}$ ). The observation data assimilated in the atmosphere 4DVAR system are land and marine surface data, upper air data (observed by radiosondes, pilot balloons, and wind profilers), tropical cyclone wind retrievals, and various satellite data which are the same observation sets as the JRA-55 reanalysis system. The second component is the ocean analysis system, which is the global ocean three-dimensional operational data assimilation system (MOVE/MRI.COM-G2; Toyoda et al. 2013). The system adopts vertical empirical orthogonal function modes calculated from historical temperature and analysis observation profiles in order to represent vertical correlations of the background errors. In-situ temperature and salinity profiles, satellite sea surface height data, and an observation-based SST dataset (COBE-SST; Ishii et al. 2005) are utilized by the ocean analysis system. The coupled ocean-atmosphere general circulation model (JMA/MRI-CGCM2) forms the third component. Its atmosphere part of the coupled model applies TL159 horizontal resolution with 60 vertical levels. Although it originated from the same version of the Global Spectral Model as JRA-55's outer model, it was modified in the several parts for CGCM to improve model climatology (Takaya et al. 2018), and these modifications can contribute the difference between the CDA and JRA-55. The ocean part of the coupled model adopts the zonal resolution of $1^{\circ}$ (approximately $100 \mathrm{~km}$ ) and the meridional resolution of $0.3^{\circ}-0.5^{\circ}$ with refinement near the equator. The oceanic analysis increments are applied to the ocean component during a 10-day interval in the second phase of the assimilation procedure by IAU, as explained above. It should be noted that SST observations are assimilated in the same manner as observations of interior ocean temperature and SST in the oceanic component of the coupled model is not directly nudged to the observed SST, which allows relatively free evolution of SST by the model. The MOVE/MRI.COMG2 and JMA/MRI-CGCM2 are parts of JMA's operational seasonal prediction system (JMA/MRI-CPS2; Takaya et al. 2018).

Using the MRI-CDA1, we performed a coupled reanalysis experiment (CDA) for the period from November 2013 to October 2015. In order to investigate the effects of the atmosphere-ocean interaction, we also conducted a uncoupled reanalysis experiment (UCPL), in which the atmospheric component is forced by COBE-SST, which are the same SSTs used as observations in the oceanic data assimilation, instead of those calculated by the ocean component of the coupled model. In both experiments, all available observational data, including satellite data, are used for atmospheric data assimilation. Additional coupled reanalysis experiments (CDAC) and uncoupled reanalysis experiments (UCPC) were also conducted, in which only in-situ observational data were used for atmospheric data assimilation, without using satellite observation data during the reanalysis 
period, in order to assess the influence of the observed data injected into the atmospheric data assimilation. This is a similar process to JRA-55C (Kobayashi et al. 2014), a reduced observation version of the JRA-55 reanalysis. The data assimilation experiment settings are summarized in Table 1. In addition, a 2-year free-run experiment (no data assimilation experiment, referred to as "FREE" hereafter) using JMA/MRI-CGCM2 started with the initial value at 28 October 2013 was also conducted in order to assess the impact of not doing data assimilation.

The analysis presented in this paper uses daily average values of precipitation and SST from these experiments. For verification of the results from the experiment, daily averaged precipitation of JRA-55 was used. Note that JRA-55 uses COBE-SST as the oceanic lower boundary condition in data assimilation. The daily precipitation of GPCPv1.2 (Huffman et al. 2001) and the COBE-SST are also used for comparison, as the observed precipitation and SST. For statistical analysis, both precipitation and SST were spatially interpolated to a $2.5^{\circ}$ grid and then, following Saha et al. (2010), smoothed by a bandpass filter of 20-100 days, in order to evaluate the intraseasonal time scale variation. The temperature profiles from a TRITON buoy (e.g., Ando et al., 2017) at the equator, $147^{\circ} \mathrm{E}$, are used for verification of CDA's near-surface temperatures. The period for the statistical analyses shown in this study is from November 2014 to April 2015. This is the same season that Saha et al. (2010) analyzed, although covering only 1 year. Although the statistical period is short, the main features are consistent with the results of previous research with a longer statistical period, as described later.

\section{SST-precipitation relationship in coupled reanalysis experiments}

Figure 2 shows the lead-lag SST-P correlation between intraseasonal variations of SST and precipitation for each grid in the observation data and in the CDA reanalysis. In the tropical Indian Ocean and tropical western Pacific, the observed SST-P correlations are positive with SST leading precipitation for 10-15 days (Fig. 2a, b). In these regions,

Table 1 Settings of data assimilation experiments

\begin{tabular}{lll}
\hline Exp. name & $\begin{array}{l}\text { Atmosphere-ocean } \\
\text { coupling }\end{array}$ & $\begin{array}{l}\text { Observation datasets used in } \\
\text { the atmospheric data assimila- } \\
\text { tion }\end{array}$ \\
\hline CDA & Yes & In-situ and satellites \\
UCPL & No & In-situ and satellites \\
CDAC & Yes & In-situ \\
UCPC & No & In-situ \\
\hline
\end{tabular}

the correlations are negative with SST lagging precipitation for 5-10 days (Fig. 2e, f), while the correlations with no lag are weakly negative (Fig. 2d). The distribution and time transition of the observed lead-lag correlation are mostly captured in the CDA reanalysis. The same plots for UCPL and FREE are shown in Fig. S1. UCPL and FREE do not result in a significant difference from the observation and CDA, as contrasted with the results of Feng et al. (2018), in which there is large difference in SST-P correlations between the coupled and uncoupled reanalyses. In this study, as the SSTs used as the lower boundary condition for UCPL are the same as those assimilated into the ocean component of CDA (both are daily COBE-SST), the resulting SSTs in CDA are similar to UCPL. A closer look, however, reveals that the amplitudes of the positive and negative correlations in the tropical Indian Ocean and tropical western Pacific are slightly smaller in UCPL. Thus, temporal variations of SSTs in the two reanalyses result in a difference, which will be the focus of the following discussion. We concentrate on assessing the tropical region where the observed relationship is strong since the SST-P relationship in the mid-latitudes is weak.

Figure 3 shows plots of the lead-lag correlation coefficients between SST and precipitation in the equatorial western Pacific $\left(10^{\circ} \mathrm{S}-10^{\circ} \mathrm{N}, 130^{\circ}-150^{\circ} \mathrm{E}\right)$. This region is the same as that described by Saha et al. (2010) and is the area that has been focused on in subsequent studies (e.g., Kumar et al. 2013; Feng et al. 2018). "OBS" indicates the correlation between GPCP precipitation and COBE-SST. The correlations between SST and precipitation in the coupled and uncoupled reanalysis experiments (CDA, UCPL) are also shown in Fig. 3, with the correlation between precipitation in JRA-55 and COBE-SST. Figure 3a shows the correlation of each precipitation with its own SST whereas Fig. 3b shows the correlation with a reference SST product (i.e., COBE-SST).

The plot from GPCP and COBE-SST indicates that precipitation shows a weak negative correlation with simultaneous SST. The SST-P correlation has a positive peak when SST leads by approximately 12 days and a negative peak when SST lags by approximately 8 days. Although these characteristics are calculated from observations over only 6 months, they are approximately in agreement with the characteristics of observations spanning a 10-year or 30-year period shown in the previous studies (e.g., Saha et al. 2010).

Figure 3 a shows that the SST-P correlation is well simulated in the CDA reanalysis (red line), although the CDA's line is shifted to the right and the negative peak becomes slightly smaller than the observation (black line). The CDA reproduces the observed SST-P relationship closer than JRA-55 (orange line) and the UCPL (blue line), although the maximum correlation of CDA occurs earlier than that the observational counterpart. In 

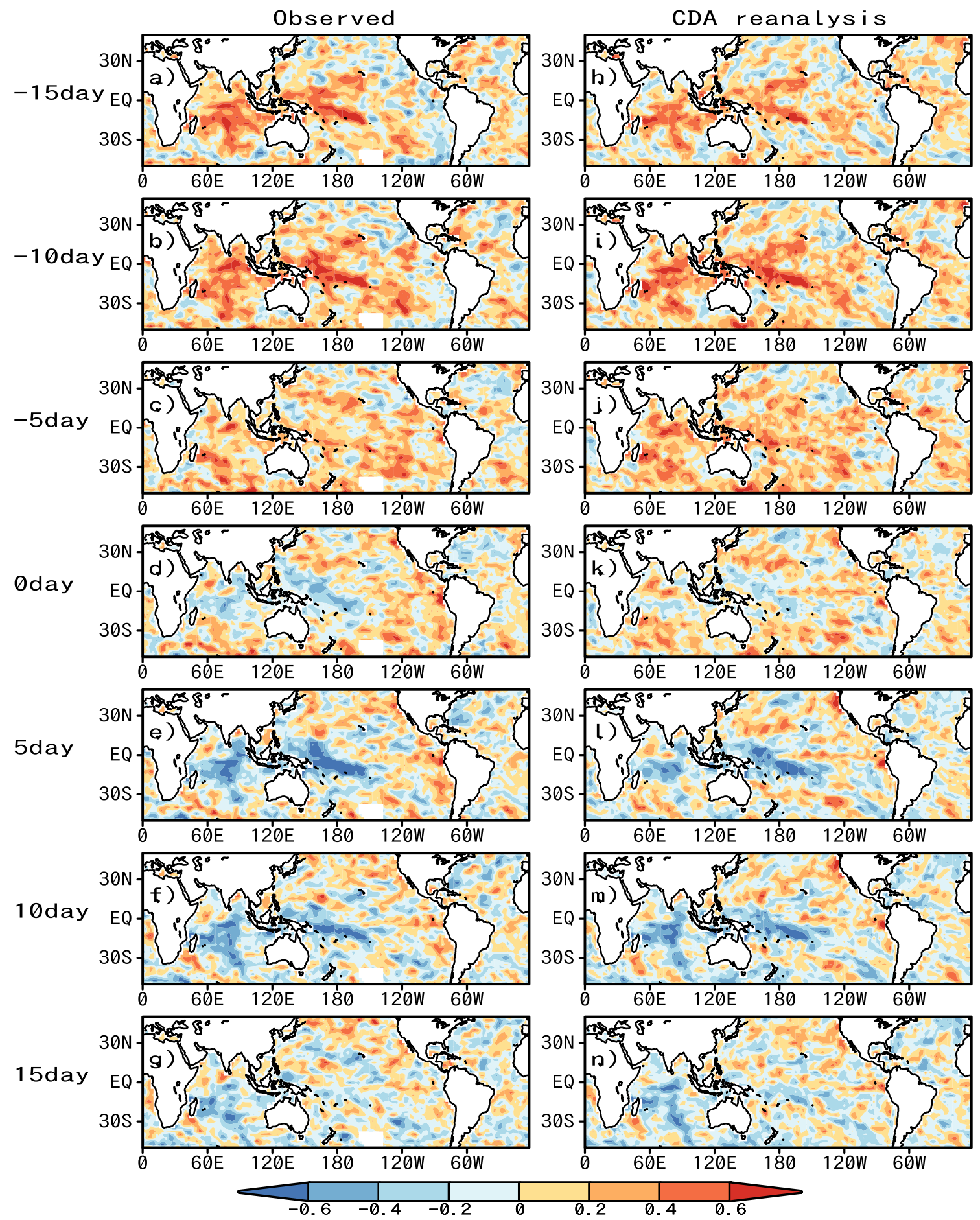

Fig. 2 SST-P intraseasonal lead-lag correlations in observations (left panels) and in the reanalysis by CDA (right panels). From the top, the correlation between local precipitation and local SST leading 15 days (a, h), SST leading 10 days (b, i), SST leading 5 days $(\mathbf{c}, \mathbf{j})$, simul-

particular, the positive and negative peaks in UCPL and JRA-55 are smaller than those in CDA. This indicates that incorporating the atmosphere-ocean interactions into the taneous SST (d, k), SST lagging 5 days (e, l), SST lagging 10 days (f, m), and SST lagging 15 days $(\mathbf{g}, \mathbf{n})$. Colors indicate correlation coefficients, where a warm color indicates a positive correlation and a cold color indicates a negative correlation

data assimilation system improves representation of the SST-P relationship. It is also noted that the lag of the drought-to-precipitation transition (cutting of the plot 


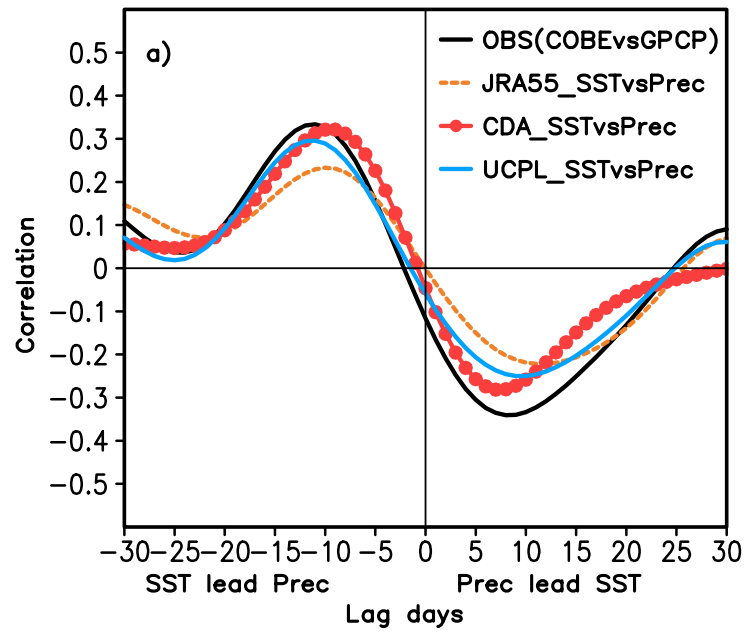

Fig. 3 Lead-lag SST-P correlations for CDA and UCPL reanalyses and observation over the tropical western Pacific (averaged over $10^{\circ}$ $\mathrm{S}-10^{\circ} \mathrm{N}, 130^{\circ}-150^{\circ} \mathrm{E}$ ). Positive numbers on the $\mathrm{x}$ axis indicate the days by which the precipitation leads the SST, and negative values indicate days by which the SST leads the precipitation. a For each of the reanalyses, their respective SSTs are used. b For each of the rea-

across the horizontal axis) behind the SST peak in CDA (1 day) is smaller than the lag estimated from observation data (3 days). This discrepancy likely reflects some defects of the system, as discussed later.

Meanwhile, Kumar et al. (2013) stated that the difference in the SST-P relationships among reanalysis datasets stems from the difference in SST in each reanalysis, and the relationship will be similar if the simulated precipitation are assessed against the same SST product. Therefore, the lead-lag correlations of precipitations in the reanalysis datasets (CDA, UCPL, JRA-55), and the observed precipitation (GPCP) with COBE-SST, are shown in Fig. $3 b$. Here it is noted that, in addition to the plot for GPCP, the plots for UCPL and JRA-55 are identical with those in Fig. 3a since the COBE-SST is the SST product that forces the atmospheric component of the coupled model in UCPL and the atmosphere model in JRA-55, and therefore is used in the calculation of the SST-P lead/lag correlation shown in Fig. 3a. The plot for CDA (red line) in Fig. 3b indicates that the lags corresponding to the correlation peaks are closer to the plot for observations (black line) than in Fig. 3a. Figure $3 b$ also shows that CDA represents the precipitation variability relative to the observed SST better than JRA-55 (orange line). In addition, the plot for CDA is almost identical to the plot for UCPL (blue line). It suggests that the difference in SST-P relationship between the CDA and UCPL reanalyses, shown in Fig. 3a, is not due to the difference in precipitation but due to the difference in SST. The improvement of SST-P relation in CDA compared to JRA-55 is considered to be mainly due to the better performance of CDA's atmospheric component

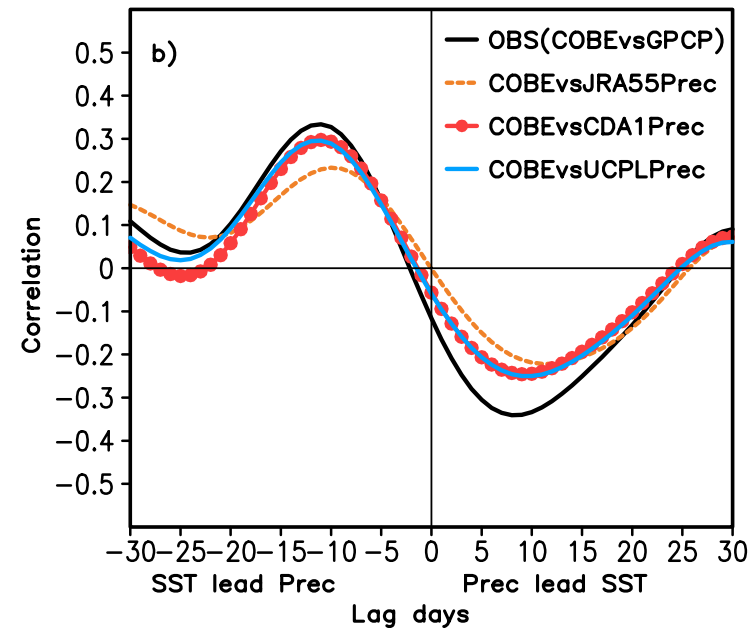

nalyses, COBE-SST is used. Here, the SST used for UCPL and JRA55 in the calculation for $\mathbf{a}$ is COBE-SST because it forces the atmospheric component of the coupled model in UCPL and the atmosphere model in JRA-55. Thus, the only difference between $\mathbf{a}$ and $\mathbf{b}$ is the red line

(the model and the assimilation system) and not due to atmosphere-ocean coupling.

The amount of precipitation in the reanalysis product is an integrated value of the 6-h forecast values in the assimilation system. It is considered that the precipitation amount in the early stage of numerical forecasts is affected more by the initial atmospheric field than by the SSTs as boundary conditions. That is, the precipitation in the reanalysis by the coupled data assimilation system is more strongly affected by the atmospheric initial field produced by assimilating the satellite observation data of the atmosphere, in addition to in-situ data, than by the SST. This is considered to be the reason the intraseasonal variation of precipitation behaves in a similar manner in the reanalyses of CDA and UCPL, even though the SSTs to which the atmospheric part of the coupled model refers differ.

In order to confirm the discussion above, the lead-lag correlations between observed SST (COBE-SST) and SSTs in the reanalyses, and those between observed precipitation (GPCP) and precipitations in the reanalyses are shown in Fig. 4. As the SST in UCPL is the COBE-SST, the lead-lag correlation between COBE-SST and the SST in UCPL (blue line) shown in Fig. 4b coincides with the COBE-SST's autocorrelation (black line). It can be also seen from Fig. $4 \mathrm{~b}$ that there is a phase delay of about 4 days in CDA SST relative to COBE-SST. In contrast, Fig. 4a shows that the phase of CDA precipitation closely follows that of the observation (GPCP), and the phase of UCPL precipitations is almost identical to that of CDA. The maximum correlation of simulated precipitation with observed one occurs at 0-day lag in both CDA and UCPL as shown in Fig. 4a. These results 


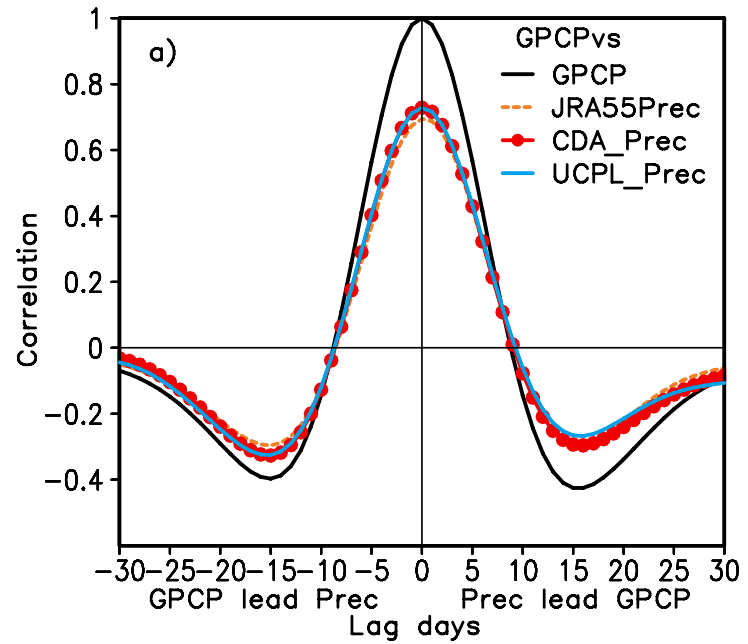

Fig. 4 a Lead-lag correlations between precipitation from different reanalyses and GPCP-observed precipitation over the tropical western Pacific (averaged over $10^{\circ} \mathrm{S}-10^{\circ} \mathrm{N}, 130^{\circ}-150^{\circ} \mathrm{E}$ ). Positive numbers on the $\mathrm{x}$ axis indicate days by which the reanalysis precipitation leads the GPCP precipitation, and negative values indicate days by which

indicate that the precipitation of the CDA is hardly affected by the SST used in the atmospheric model.

In order to confirm the influence of the observation data used in atmospheric data assimilation on the behavior of precipitation, the reanalysis experiments using coupled and uncoupled system, which assimilates only in-situ observations without satellite observations, are performed (CDAC and UCPC). Figure 5 shows plots of the lead-lag correlation coefficients between SST and precipitation for CDAC, UCPC and observations. Figure 5a, in which the SSTs in corresponding reanalyses are used, indicates that the correlations for the coupled reanalysis (CDAC, red line) are closer

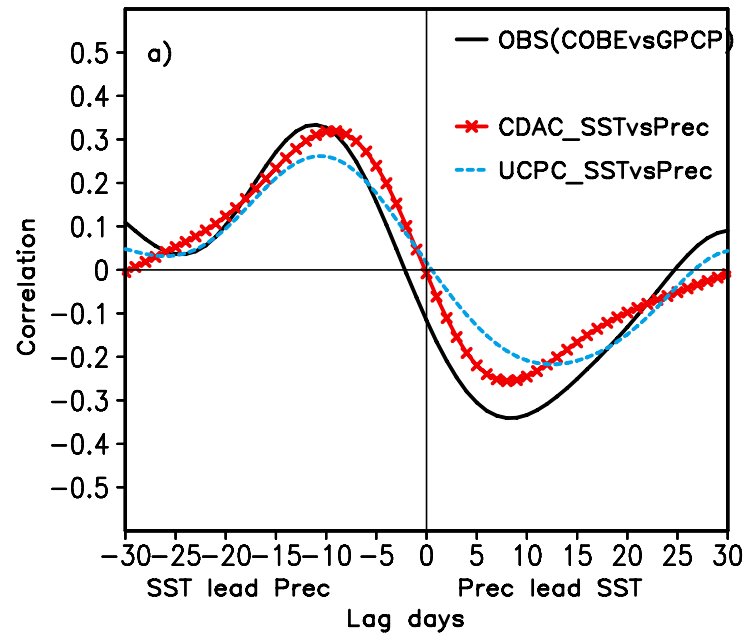

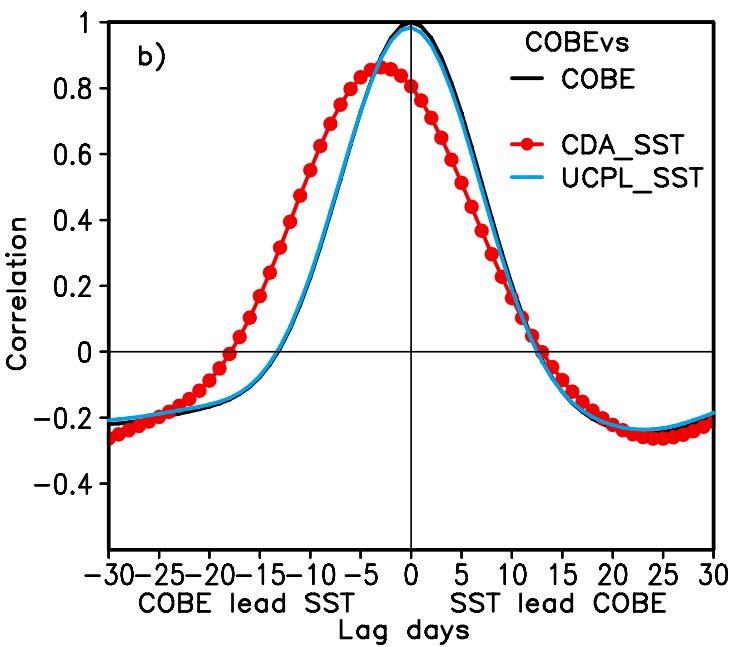

the GPCP precipitation leads the reanalysis precipitation. b Lead-lag correlations between SSTs from different reanalyses and the COBESST over the tropical western Pacific. Negative lag in days on the $\mathrm{x}$ axis indicates days by which the COBE-SST leads SSTs in other reanalyses

to the observational counterpart than those for the uncoupled reanalysis (UCPC, blue line), although the maximum correlation of CDAC occurs earlier than that of the observational counterpart. In addition, the relationship degrades in both CDAC (red line) and UCPC (blue line) compared to those in CDA and UCPL (Fig. 3a), respectively. The degree of degradation in UCPC relative to UCPL is larger than the degradation of CDAC relative to CDA. In Fig. 5b, in which the COBE-SST is used for all lines, it can be seen that CDAC's SST-P relationship (red line) is better than that of UCPC (blue line), which implies the possibility that CDAC has better precipitation reproducibility than UCPC does. This

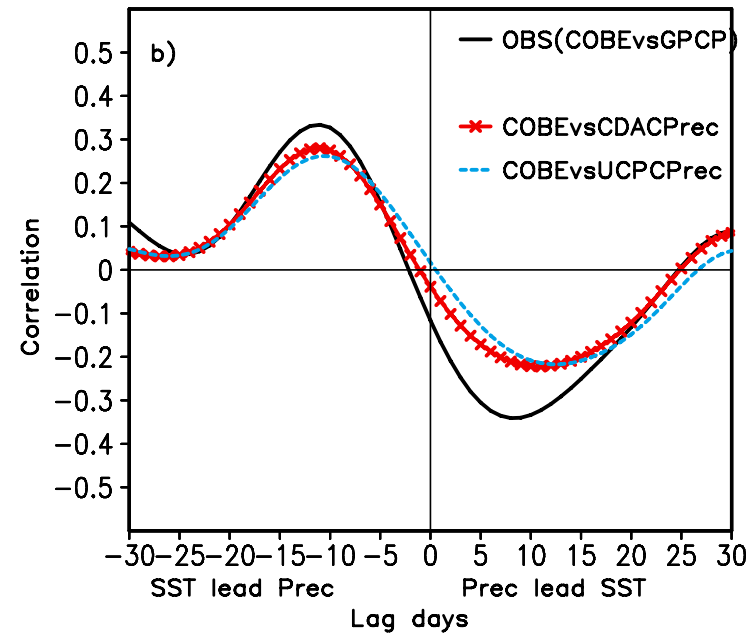

Fig. 5 Same as Fig. 3, but for reanalyses produced by the CDAC and UCPC experiments, which are the reanalyses without using satellite observations 
is in contrast to Fig. 3b, in which the CDA and UCPL lines are almost identical.

These results suggest that when using satellite observations, constraints in the atmospheric component by data assimilation are sufficiently strong and, therefore, precipitation in CDA and UCPL are hardly affected by the SSTs. In contrast, when satellite observations are excluded as in CDAC and UCPC, it is considered that the atmospheric components are less strongly constrained and allowed freely to respond to the SSTs to some extent. The fact that CDAC's precipitation phase relative to observed SST is closer to observed precipitation than UCPC suggests that the coupled model's physics can complement relatively weak observational constraints, leading to smaller degradation of the SST-P relationship in CDAC than in UCPC.

\section{Relationships among surface heat flux, SST, and oceanic near-surface temperatures}

In this section, we discuss the surface heat flux affecting SST variation in the coupled data assimilation experiment. In the atmosphere-ocean coupled model, the surface heat flux given from the atmosphere to the ocean plays an essential role in determining the SST. In the coupled data assimilation system, the SST calculated by the atmosphere-ocean coupled model are further corrected using the SST observation data. In order to assess the role of surface heat flux in determining the SST, the relationships between surface heat flux variations and SST variation in the coupled experiments are examined.

Figure 6a shows the lead-lag regression relationship between the surface heat flux and the SST of the intraseasonal timescale variations in the tropical western Pacific. Here, positive surface heat flux indicates cooling of the sea surface. As mentioned in the previous section, the CDA SST fluctuation lags behind COBE-SST, resulting in the smaller lag between the SST peak and the drought-to-precipitation transition in CDA (the black dashed line that crosses the horizontal axis at -1 day) than in observation (the gray line that crosses the horizontal axis at -3 day). Among the four components of the surface heat flux shown in Fig. 6a, the short-wave radiation makes the largest contribution to the net heat flux, followed by the latent heat flux contribution, while the other two components make only small contributions. Both of the two main flux components and the net heat flux change their signs nearly simultaneously to the precipitation.

These results suggest the following process: the phase relationship of CDA's precipitation relative to SST is strongly constrained by the assimilation in the atmospheric component. Precipitation strongly controls the short-wave radiation which makes the largest contribution to the net heat flux. In CDA, the lag between the SST peak and the droughtto-precipitation transition is smaller than in the observation, indicating that the MRI-CDA1 system has some errors in representing the relative roles of the surface heat flux and the oceanic processes (advection and mixing) in determining CDA's SST variation, which will be discussed later.

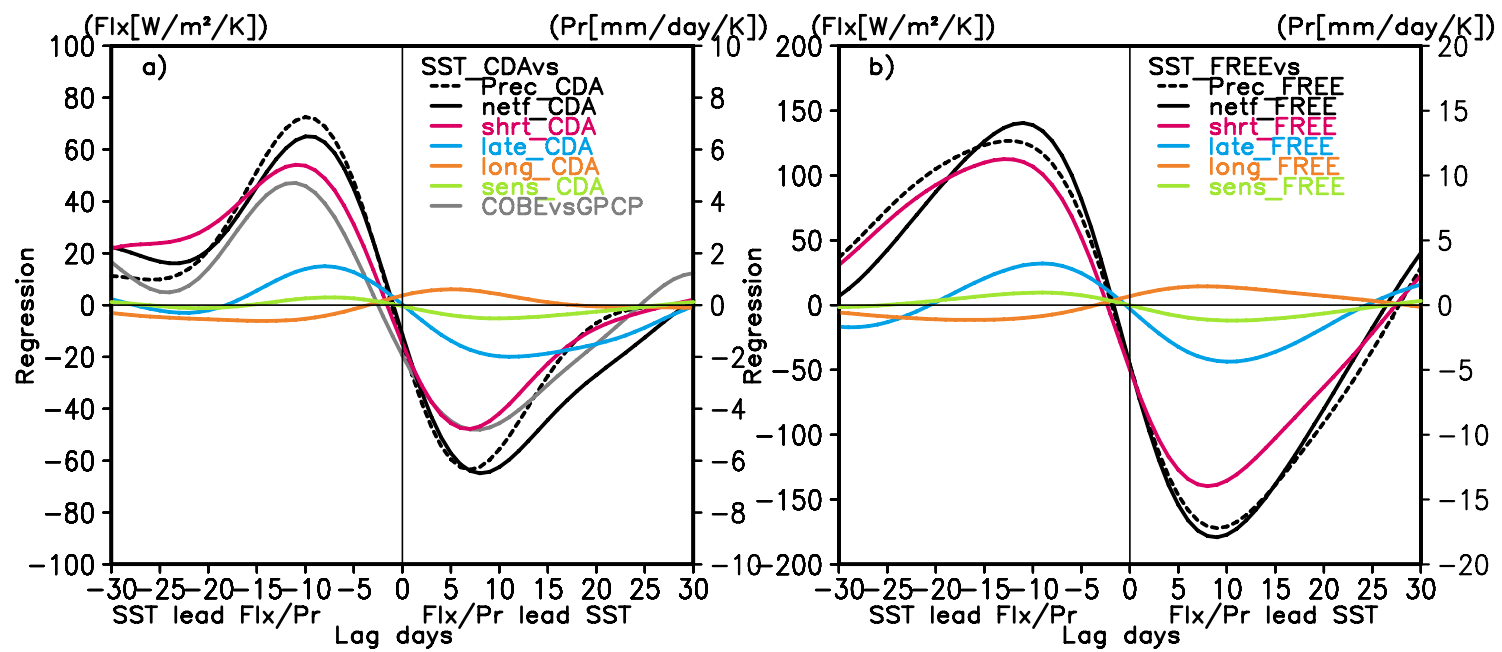

Fig. 6 Lead-lag regression relationship between a the surface heat flux and the SST for CDA reanalysis and $\mathbf{b}$ simulated heat flux and simulated SST in the atmosphere-ocean coupled model (FREE) over the tropical western Pacific (averaged over $10^{\circ} \mathrm{S}-10^{\circ} \mathrm{N}, 130^{\circ}-150^{\circ}$ E). "Prec", "netf", "shrt", "late", "long" and "sens" in the legend indicate precipitation, net heat flux, short-wave radiation, latent heat flux, long-wave radiation and sensible heat flux, respectively. The left-hand axis shows the regression coefficient for heat flux (unit: W/ $\mathrm{m}^{2} / \mathrm{K}$ ). The right-hand axis shows the regression coefficient for precipitation (unit: $\mathrm{mm} / \mathrm{day} / \mathrm{K}$ ). The vertical scale differs between $\mathbf{a}$ and b 
As shown in Fig. 6b, the FREE run without data assimilation also simulates the phase relationship among SST, precipitation, and flux components qualitatively, similar to CDA, although the lag between the timing of the net flux variation components sign change and the SST peak is smaller in CDA than in FREE. The ability of the coupled model (FREE) to reproduce such a process might contribute to CDAC's ability to complement the sparseness of observations (as mentioned in the discussion of Fig. 5b). The simulated fields in FREE cannot be validated against observations because of their large deviations from the real temporal variations. In contrast, the CDA experiment realistically simulates the intraseasonal variation of precipitation and SST to some extent, and related physical processes including heat flux components are represented in the model to be consistent with precipitation and SST. The MRI-CDA1 system is, therefore, considered useful for diagnosing such temporal variations and related processes based on a realistic
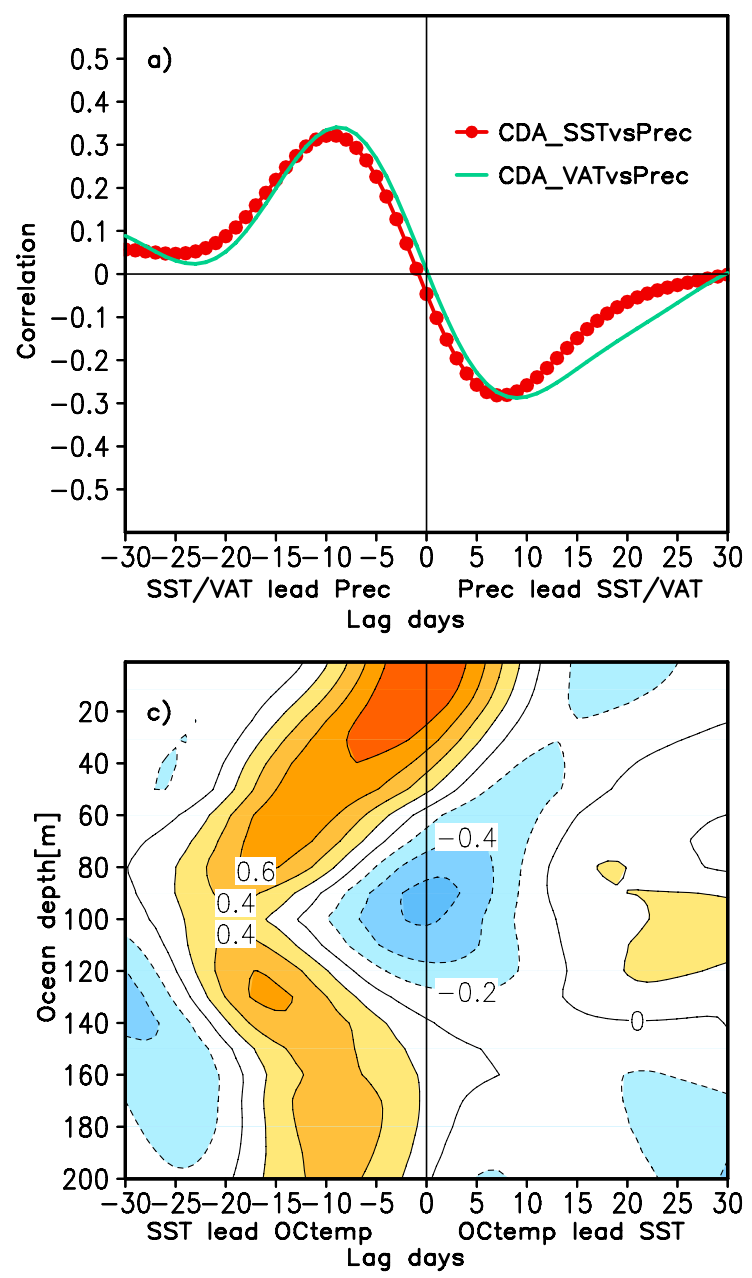

Fig. 7 a Lead-lag SST-P correlations and VAT50-precipitation correlations for CDA reanalysis over the tropical western Pacific (averaged over $10^{\circ} \mathrm{S}-10^{\circ} \mathrm{N}, 130^{\circ}-150^{\circ} \mathrm{E}$ ). "VAT50" is the vertically averaged temperature from the surface to the $50 \mathrm{~m}$-depth. b Lead-lag SST- time series of the state of the coupled atmosphere-ocean system.

SST's temporal variation is thought to be determined by surface heat flux and oceanic processes. Although, as mentioned above, CDA simulates the qualitative timing relationship between SST and heat flux realistically, the CDA is likely to have some errors in relative oceanic processes, possibly resulting in the timing error of SST variation (CDA SST lagging behind COBE-SST).

To trace the possible source of this error, the temporal variation of the near-surface temperature in the CDA experiment is examined. Figure 7 a shows the lead-lag correlation (green line) between the precipitation and the vertically averaged temperature from the surface to the $50 \mathrm{~m}$-depth (VAT50) overlaid on the lead-lag correlation (red line) between the precipitation and the SST. It can be seen from this figure that VAT50's temporal peak coincides with the drought-to-precipitation transition, indicating that the heat
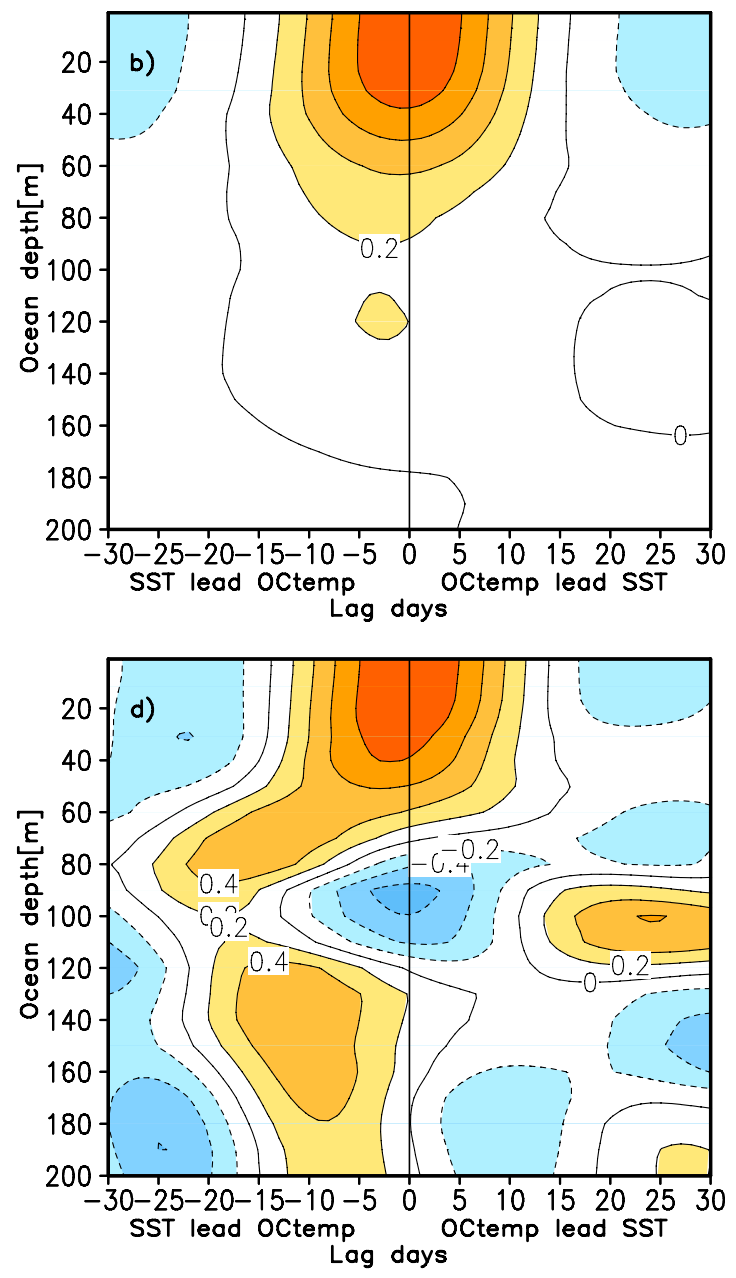

ocean temperature correlations for CDA reanalysis over the tropical western Pacific (averaged over $10^{\circ} \mathrm{S}-10^{\circ} \mathrm{N}, 130^{\circ}-150^{\circ} \mathrm{E}$ ). Contour interval is 0.2 . c Same as b but for TRITON buoy data at $147^{\circ} \mathrm{E}$, Equator. d Same as $\mathbf{b}$ but for CDA reanalysis at $147^{\circ} \mathrm{E}$, Equator 
budget is nearly balanced within the top $50 \mathrm{~m}$ of the ocean in the target region, while the SST peak slightly leads the drought-to-precipitation transition. In Fig. 7b, the lead-lag correlations between the SST and the near-surface temperatures at the top $200 \mathrm{~m}$ depths are plotted. It shows that the temporal variations of the near-surface temperatures lag behind SST, and the lag increases with depth in the layer approximately above $50 \mathrm{~m}$. This suggests that a heat signal injected at the surface is propagated downward into the nearsurface ocean, and due to this vertical heat transport, the SST reaches its peak earlier than the drought-to-precipitation (heating-to-cooling) transition. Oceanic processes including vertical mixing are considered to contribute to this vertical heat transport. For comparison between observations and CDA, plots similar to Fig. 7b are presented in Fig. 7c and $\mathrm{d}$, but for the observed temperature profile by the TRITON buoy at the equator, $147^{\circ} \mathrm{E}$, and for the CDA's temperature profile at the closest grid point to the buoy, respectively. In the target region, there are only two TRITON buoys whose data cover the analysis period, and for comparison, we show here the plot using the equatorial buoy, as the other (at $2^{\circ} \mathrm{N}$, $147^{\circ} \mathrm{E}$ ) shows similar variability. Here, it should be noted that the TRITON buoys made temperature measurements only at $1,25,50,75,100,125,200 \mathrm{~m}$ and those data are interpolated into the model levels $(1,3.5,7,11.5,23.5$, $31 \mathrm{~m}$, and every $10 \mathrm{~m}$ between 40 and $190 \mathrm{~m}$ ). It can be seen from these plots that the vertical propagation of the temperature signal is much faster in the CDA than in observation, suggesting that the oceanic processes related to the vertical heat transport, including vertical mixing, are too intense in the CDA. Thus, although the CDA achieves qualitatively good simulation, in that the SST peak leads the drought-toprecipitation transition, the lag between them is smaller than observation because of the error in the oceanic processes related to vertical heat transport. It should be noted that the lag of the drought-to-precipitation (warming-to-cooling) transition behind SST peaks in FREE is larger than that in CDA (Fig. 6), suggesting a possibility that the vertical heat propagation in the near-surface ocean is faster in CDA. We infer that modification of mixed layer depth and near-surface water density stratification by oceanic data assimilation in CDA causes this difference.

In light of the above considerations on the processes determining SST in CDA, we return to Fig. 3. In Fig. 3b, the correlations between the reanalysis precipitation and the observed SST for CDA (red line) and UCPL (blue line) nearly overlap, and are both weaker than the observational correlation (black line), probably due to the error in representation of precipitation by the atmospheric data assimilation system. In Fig. 3a, the UCPL line is essentially the same as in Fig. 3b, because the COBE-SST is prescribed as the lower boundary condition. For CDA, on the other hand, the correlation between the reanalysis precipitation and SST is stronger than the counterpart of Fig. $3 b$, and it is considered to be due to the adjustment of the SST field to the atmospheric forcing in CDA. Here it should be emphasized that the COBE-SST, which forces the atmosphere component in UCPL, is a daily-varying SST product. Feng et al. (2018) argued that the better representation of SST-P relation in their coupled reanalysis is brought by reconstruction of daily-intraseasonal SST variability not present in the monthly SST product used in their uncoupled reanalysis. But we show that the coupled reanalysis improves the SST-P relationship over uncoupled reanalysis, even when dailyvarying SST is used in the uncoupled reanalysis.

\section{Summary}

In this study, the SST-P intraseasonal relationships, as an indicator of atmosphere-ocean interaction, are examined in order to evaluate the MRI-CDA1 coupled atmosphericocean data assimilation system. The CDA experiment adequately reproduces the observed lead-lag correlation between precipitation and SST. In addition, the SST-P relationship in the tropical western Pacific presented in the CDA follows the observed relationship more closely than that of the uncoupled assimilation (UCPL) experiment. However, when a single observed SST is considered instead of the simulated SSTs, the phase relationships of precipitation in the CDA experiment and that for the UCPL experiment are almost identical. Therefore, it is considered that the difference of the SST-P relationship between CDA and UCPL, shown in Fig. 3a, is caused by the difference of SSTs that forced the atmosphere component. Thus, the impacts of atmosphere-ocean coupling on the DA system can be seen more clearly in the SST variation than in the precipitation, probably because observational constraints are stronger in the atmosphere component than in the ocean component in the MRI-CDA1 system.

In other words, the intraseasonal variation of precipitation of CDA is influenced more strongly by the atmospheric field constrained by data assimilation than by the SSTs used as the boundary conditions. In the targeted period, a large amount of satellite observation data is used for atmospheric data assimilation, and the atmospheric conditions such as the total amount of precipitable water in the atmosphere are determined robustly by the observation data used in the data assimilation system. Since precipitation is generated in the early stage of the prediction in the data assimilation system and strongly affected by the atmospheric initial conditions constrained by those observations, the intraseasonal precipitation represented in the CDA and UCPL reanalyses behave very similarly. In the experiments (CDAC and UCPC) in which only conventional observations (without satellite observations) are assimilated in the atmospheric component, 
the coupling effect on the atmospheric assimilation can be seen in that CDAC better reproduces the observed SST-P relationship than UCPC does. The ability of the coupled model (FREE) to simulate the SST-P relationship realistically may contribute to CDAC's better performance.

In addition, the sea surface heat flux, which is consistent with CDA's atmospheric condition, forces the ocean component of the coupled atmosphere-ocean model of the data assimilation system and controls the SST variation. As a result, the SST of CDA lags behind the observed SST. By examining the temporal variation of the ocean near-surface temperature, it is suggested that CDA overestimates the downward heat propagation compared to the observation, causing the error in the SST temporal variation. To improve the data assimilation system and the atmosphere-ocean coupled model, it is necessary to pay attention to near-surface ocean processes as well as the contribution of sea surface heat flux relative to oceanic processes in determining the SST. For the development and validation of near-surface oceanic processes, such as downward propagation of the heat signals, in a coupled model/CDA system, oceanic temperature data with high vertical and temporal resolutions are very helpful, and we expect the enhanced observation in the oceanic mixed layer by the tropical Pacific mooring buoy array planned by the Topical Pacific Observing System 2020 (TPOS2020) project (Cravatte et al. 2016; Smith et al. 2019) will make an essential contribution to this purpose.

In the CDA experiment improvement of atmospheric fields by atmosphere-ocean coupling could hardly be seen because the atmospheric component is strongly constrained by data assimilation and hardly affected by SST. When atmospheric constraints are relaxed, as in the CDAC and UCPC experiments, the coupling effect becomes more evident, although overall performance is degraded. It is notable that the coupled system is less degraded by the removal satellite DA in the atmosphere. The coupled system does not really improve products with the present observing network but it is more robust to changes in that network. The intraseasonal variation of SST and precipitation, and related physical processes including surface heat flux are simulated realistically in CDA to some extent. Therefore, a CDA system is considered useful for diagnosing such temporal variations based on a realistic time series of the state of the coupled atmosphere-ocean system. In addition, it is a promising tool to estimate historical atmospheric fields, particularly the precipitation field, which are consistent with the historical oceanic variation, because it is more accurate than those generated by uncoupled data assimilation systems particularly for the period in which modern satellite data are not available.

Even if the observation data are not sufficient, CDA system has a possibility to obtain a more physically consistent atmosphere and ocean fields by simulating more realistic SST variations based on ocean model physics and ocean-atmosphere interaction and also with the aid of data assimilation. Observation data has a limit in terms of temporal/spatial resolution and accuracy, particularly in the pre-satellite era and even in the present. Therefore, it is still worthwhile to use atmosphere ocean coupled DA system to compensating for those observation data limits.

Although the results obtained in this study include uncertainty related to a short period for statistical analysis, the results were consistent with previous studies using decades of experimental data. To increase statistical reliability of our results, we need to extend the experiment period and perform verification including a significance test, which we would like to leave as future tasks.

Acknowledgements The authors are grateful to the anonymous reviewers for their constructive comments. The authors would like to thank T. Ishibashi and Y. Takaya for their significant contributions in building the execution environment of MRI-CDA1 in the MRI supercomputer system. This work was supported by JSPS KAKENHI Grant Number JP17H00728. Figures are prepared using GrADS (http://cola.gmu.edu/ grads/). The daily precipitation data, GPCPv1.2, is downloaded from https://www1.ncdc.noaa.gov/pub/data/gpcp/daily-v1.2/data/. The daily COBE-SST can be obtained by request to the Climate Prediction Division, JMA. The near-surface ocean temperature data from TRITON buoy is downloaded from http://www.jamstec.go.jp/jamstec/TRITO N/real_time/. The JRA-55 reanalysis data are publicly available from the JMA Data Dissemination System and collaborative organizations (detailed information is available on the JRA-55 web site https://jra. kishou.go.jp/JRA-55/index_en.html). The daily averaged precipitation, surface fluxes, SST and ocean near-surface temperature simulated by the coupled reanalysis experiments (CDA, UCPL, CDAC and UCPC) and model free run experiment (FREE) can be obtained by request to the authors. The source codes of the statistical analysis tools written in Fortran and GrADS scripts are also available from the authors upon request.

Open Access This article is licensed under a Creative Commons Attribution 4.0 International License, which permits use, sharing, adaptation, distribution and reproduction in any medium or format, as long as you give appropriate credit to the original author(s) and the source, provide a link to the Creative Commons licence, and indicate if changes were made. The images or other third party material in this article are included in the article's Creative Commons licence, unless indicated otherwise in a credit line to the material. If material is not included in the article's Creative Commons licence and your intended use is not permitted by statutory regulation or exceeds the permitted use, you will need to obtain permission directly from the copyright holder. To view a copy of this licence, visit http://creativecommons.org/licenses/by/4.0/.

\section{References}

Ando K, Kuroda Y, Fujii Y, Fukuda T, Hasegawa T, Horii T, Ishihara Y, Kashino Y, Masumoto Y, Mizuno K, Nagura M, Ueki I (2017) Fifteen years progress of the TRITON array in the Western Pacific and Eastern Indian Oceans. J Oceanogr 73:403-426

Arakawa O, Kitoh A (2004) Comparison of local precipitation-SST relationship between the observation and a reanalysis dataset. Geophys Res Lett 31:L12206. https://doi.org/10.1029/2004G L020283 
Balmaseda M, Anderson D (2009) Impact of initialization strategies and observations on seasonal forecast skill. Geophys Res Lett 36:L01701. https://doi.org/10.1029/2008GL035561

Bloom SC, Takacs LL, Da Silva AM, Ledvina D (1996) Data assimilation using incremental analysis updates. Mon Weather Rev 124:1256-1271

Cravatte S, Kessler WS, Smith N, Wijffels SE, and Contributing Authors (2016) First report of TPOS 2020. GOOS-215, p 200. http://tpos2020.org/first-report/. Accessed 5 Jan 2021

Dee DP, Uppala SM, Simmons AJ, Berrisford P, Poli P, Kobayashi S et al (2011) The ERA-interim reanalysis: configuration and performance of the data assimilation system. Q J R Meteorol Soc 137:553-597

Feng X, Haines K, Liu C, de Boisséson E, Polo I (2018) Improved SST-precipitation intraseasonal relationships in the ECMWF coupled climate reanalysis. Geophys Res Lett 45:3664-3672. https:// doi.org/10.1029/2018GL077138

Fujii Y, Nakaegawa T, Matsumoto S, Yasuda T, Yamanaka G, Kamachi M (2009) Coupled climate simulation by constraining ocean fields in a coupled model with ocean data. J Clim 22:5541-5557. https ://doi.org/10.1175/2009JCLI2814.1

Fujii Y, Kobayashi C, Ishibashi T, Takaya Y (2019) Development of weakly coupled atmosphere-ocean data assimilation system and the evaluation of the coupled reanalysis in JMA/MRI. In: GODAE OceanView symposium, OceanPredict ' 19

Fujii Y, Ishibashi T, Yasuda T, Takaya Y, Kobayashi C, Ishikawa I (2021) Improvements in tropical precipitation and sea surface air temperature fields in a coupled atmosphere-ocean data assimilation system. Q J R Meteorol Soc (accepted)

Hudson D, Alves O, Hendon HH, Lim E, Liu G, Luo J-J, MacLachlan C, Marshall AG, Shi L, Wang G, Wedd R, Young G, Zhao M, Zhou X (2017) ACCESS-S1: the new Bureau of Meteorology multi-week to seasonal prediction system. J South Hemisph Earth Syst Sci 67(3):132-159. https://doi.org/10.22499/3.6703.001

Huffman GJ, Adler RF, Morrissey MM, Bolvin DT, Curtis S, Joyce R, McGavock B, Susskind J (2001) Global precipitation at one-degree daily resolution from multisatellite observations. J Hydrometeorol 2:36-50. https://doi.org/10.1175/15257541(2001)002\%3c0036:GPAODD\%3e2.0.CO;2

Ishii M, Shouji A, Sugimoto S, Matsumoto T (2005) Objective analyses of sea-surface temperature and marine meteorological variables for the 20th century using ICOADS and the KOBE collection. Int J Climatol 25:865-879. https://doi.org/10.1002/joc.1169

Johnson SJ, Stockdale TN, Ferranti L, Balmaseda MA, Molteni F, Magnusson L, Tietsche S, Decremer D, Weisheimer A, Balsamo G, Keeley SPE, Mogensen K, Zuo H, Monge-Sanz BM (2019) SEAS5: the new ECMWF seasonal forecast system. Geosci Model Dev 12:1087-1117. https://doi.org/10.5194/gmd-12-1087-2019

Kalnay E et al (1996) The NCEP/NCAR 40-year reanalysis project. Bull Am Meteorol Soc 77:437-470

Kanamitsu M, Ebisuzaki W, Woolen J, Potter J, Fiorino M (2002) NCEP/DOE AMIP-II reanalysis (R-2). Bull Am Meteorol Soc 83:1631-1643

Kobayashi C et al (2014) Preliminary results of the JRA-55C, an atmospheric reanalysis assimilating conventional observations only. Sola 10:78-82
Kobayashi S, Ota Y, Harada Y, Ebita A, Moriya M, Onoda H, Onogi K, Kamahori H, Kobayashi C, Endo H, Miyaoka K, Takahashi K (2015) The JRA-55 reanalysis: general specifications and basic characteristics. J Meteorol Soc Jpn 93:5-48. https://doi. org/10.2151/jmsj.2015-001

Kumar A, Zhang L, Wang W (2013) Sea surface temperature-precipitation relationship in different reanalyses. Mon Weather Rev 141:1118-1123. https://doi.org/10.1175/MWR-D-12-00214.1

MacLachlan C, Arribas A, Peterson KA, Maidens A, Fereday D, Scaife AA, Gordon M, Vellinga M, Williams A, Comer RE, Camp J, Xavier P, Madec G (2015) Global seasonal forecast system version 5 (GloSea5): a high-resolution seasonal forecast system. Q J R Meteorol Soc 141:1072-1084. https://doi.org/10.1002/qj.2396

Mulholland DP, Laloyaux P, Haines K, Balmaseda M (2015) Origin and impact of initialization shocks in coupled atmosphereocean forecasts. Mon Weather Rev 143:4631-4644. https://doi. org/10.1175/MWR-D-15-0076.1

Japan Meteorological Agency (2013) Outline of the operational numerical weather prediction at the Japan Meteorological Agency. In: WMO technical progress report on the global data-processing and forecasting system and numerical weather prediction research, JMA, Japan, p 188. http://www.jma.go.jp/jma/jma-eng/jma-cente r/nwp/nwp-top.htm. Accessed 5 Jan 2021

Penny S, Akella S, Alves O, Bishop C, Buehner M, Chevallier M, Counillon F, Draper C, Frolov S, Fujii Y, Karspeck A, Kumar A, Laloyaux P, Mahfouf J-F, Martin M, Peña M, de Rosnay P, Subramanian A, Tardif R, Wang Y, Wu X (2017) Coupled data assimilation for integrated earth system analysis and prediction: goals, challenges and recommendations, technical report: WWRP 2017-3. World Meteorological Organization, Geneva

Rienecker MM et al (2011) MERRA-NASA's modern-era retrospective analysis for research and applications. J Clim 24:3624-3648. https://doi.org/10.1175/JCLI-D-11-00015.1

Saha $\mathrm{S}$ et al (2010) The NCEP climate forecast system reanalysis. Bull Am Meteorol Soc 8:1015-1058. https://doi.org/10.1175/2010B AMS3001.1

Smith N et al (2019) Tropical Pacific observing system. Front Mar Sci 6:31. https://doi.org/10.3389/fmars.2019.00031

Takaya Y, Hirahara S, Yasuda T et al (2018) Japan Meteorological Agency/Meteorological Research Institute-Coupled Prediction System version 2 (JMA/MRI-CPS2): atmosphere-land-oceansea ice coupled prediction system for operational seasonal forecasting. Clim Dyn 50:751-765. https://doi.org/10.1007/s0038 2-017-3638-5

Toyoda T, Fujii Y, Yasuda T, Usui N, Iwao T, Kuragano T, Kamachi M (2013) Improved analysis of seasonal-interannual fields using a global ocean data assimilation system. Theor Appl Mech Jpn 61:31-48. https://doi.org/10.11345/nctam.61.31

Publisher's Note Springer Nature remains neutral with regard to jurisdictional claims in published maps and institutional affiliations. 